\title{
Tuning High Order Geometric Aberrations in Quadrupole-Octupole Correctors
}

\author{
N. Dellby ${ }^{1}$, G.J. Corbin ${ }^{1}$, Z. Dellby ${ }^{1}$, T.C. Lovejoy ${ }^{1}$, Z.S. Szilagyi ${ }^{1}$, M.F. Chisholm ${ }^{2}$ and O.L. Krivanek ${ }^{1}$ \\ ${ }^{1}$ Nion Co., 1102 Eighth St, Kirkland, WA 98033, USA \\ ${ }^{2}$ Materials Science and Technology Division, Oak Ridge National Lab., Oak Ridge, TN 37831, USA.
}

The resolution attained by aberration correction in both conventional and scanning transmission electron microscopy (CTEM and STEM) at $300 \mathrm{keV}$ has reached $0.5 \AA$ already some time ago, and the emphasis in corrector development has thus shifted to the resolution at lower primary energies of around $50 \mathrm{keV}$. The attainable resolution at $<200 \mathrm{keV}$ is typically more limited by chromatic aberrations than by geometric ones, and this has led to a decreased interest in improving correctors of geometric aberrations. The chromatically-limited resolution is proportional to $\left(\mathrm{C}_{\mathrm{c}} \Delta \mathrm{E}\right)^{0.5}$, where $\mathrm{C}_{\mathrm{c}}$ is the chromatic aberration coefficient, and $\Delta \mathrm{E}$ the energy spread of the beam. Two paths to improving the chromatic resolution limit are therefore available: decrease (or null) $\mathrm{C}_{\mathrm{c}}$ with a chromatic corrector, or decrease $\Delta \mathrm{E}$. Both paths have been explored, with promising results [1-3]. This means that attention now needs to shift back to the correction of geometric aberrations, in particular to aberrations higher than $3^{\text {rd }}$ order.

Two types of geometric aberrations are of concern: primary ones allowed even by perfectly aligned corrector systems, which start at $7^{\text {th }}$ order for advanced present-day correctors [4-5]; and parasitic ones that arise due to imperfections in manufacturing, inhomogeneities of magnetic materials, and imprecise alignment. The parasitic aberrations are normally several orders of magnitude smaller than the primary aberrations, but because they are typically only corrected up to $3^{\text {rd }}$ order, their effects can be dominant.

Two principal ways are available for dealing with the parasitic aberrations: 1) "blind" alignment that relies on improved manufacturing precision and alignment procedures to reduce the aberrations to acceptable levels, without being able to address them individually; and 2) adding optical elements that give complete control over the aberrations. As shown by the HAADF STEM image of Fig. 1, the improved alignment approach can readily reach resolution of the order of $0.5 \AA$ at $200 \mathrm{keV}$, which only necessitates correction to $31 \mathrm{mrad}$ half-angle in the STEM mode. To reach the same resolution at $40 \mathrm{keV}$, however, correction to $73 \mathrm{mrad}$ is required in the STEM mode (and to $120 \mathrm{mrad}$ in the CTEM mode). This is probably not attainable reproducibly without the second approach.

The strategies for controlling different parasitic aberrations vary with the aberration type. For the highest multiplicity aberration of any order $-C_{n, n+1}$ in our "Arabic numeral-style" notation [6] - a $2 n+2$ multipole located in a plane with a round beam addresses the aberration directly. Thus a 10-pole can "tune" 5-fold astigmatism $\mathrm{C}_{4,5}$, a 12-pole can tune 6-fold astigmatism $\mathrm{C}_{5,6}$, etc. If the plane of the multipole is imaged into the principal plane of the objective lens $(\mathrm{OL})$, then no further aberrations arise. This type of conjugate imaging is used for projecting the principal planes of $\mathrm{C}_{3} / \mathrm{C}_{5}$ correctors into the OL.

To control aberrations $\mathrm{C}_{\mathrm{n}, \mathrm{m}}$ for which $\mathrm{m}<\mathrm{n}+1$, one needs to employ "combination aberrations". These are excited when an element $U$ causing aberration Cnu,muis allowed to distort the beam in an element $V$ creating combination aberration $\mathrm{C}_{\mathrm{nv}, \mathrm{mv}}$. The leading aberrations that arise in this situation are given by [6]:

$$
\mathrm{C}_{\mathrm{N} 1, \mathrm{M} 1}=\mathrm{C}_{\mathrm{nu}+\mathrm{nv}-1,|\mathrm{mu}-\mathrm{mv}|}
$$

and also, when $\mathrm{mu}+\mathrm{mv} \leq \mathrm{nu}+\mathrm{nv}$

$$
\mathrm{C}_{\mathrm{N} 2, \mathrm{M} 2}=\mathrm{C}_{\mathrm{nu}+\mathrm{nv}-1, \mathrm{mu}-\mathrm{mv}}
$$


(As an exercise for agile minds, we invite the reader to express the above relations using the "Roman numeral style" aberration notations employed in references [1] and [5].)

Examples of combination aberrations that can be used to address different parasitic aberrations are given in Table 1. Lines 1-5 show correction schemes that are used already. Line 1 shows how two-fold astigmatism $\left(\mathrm{C}_{1,2}\right)$ is controlled in sextupole correctors, by shifting the beam (giving displacement $\left.\mathrm{C}_{0,1}\right)$ incident on a sextupole. Line 2 shows how axial coma $C_{2,1}$ is controlled in most correctors - by shifting the beam in the OL. Line 3 shows how 3 -fold astigmatism $\mathrm{C}_{2,3}$ is controlled in octupole correctors - by shifting the beam in an octupole. Line 4 shows how negative spherical aberration is created in sextupole correctors, and line 5 how $\mathrm{C}_{5,0}$ is adjusted in most $\mathrm{C}_{3} / \mathrm{C}_{5}$ correctors: by mis-projecting the corrector into the OL. Lines 6-12 show examples of various strategies for correcting high order parasitic aberrations. Line 13 shows how $\mathrm{C}_{5,0}$ could in principle be corrected using two octupoles in an arrangement similar to sextupole correctors of $\mathrm{C}_{3,0}$, as was once suggested [7] but never built, most likely because implementing the $\mathrm{C}_{5,0}$ correction scheme of line 5 is much simpler.

In practice, implementing controls for the $4^{\text {th }}$ and higher-order parasitic aberrations in a quadrupole-octupole corrector requires incorporating additional sextupoles in non-octupole planes, and preferably also incorporating at least one 12-pole in an octupole plane that contains a round beam. Results from correctors that contain these elements will be shown at the meeting.

\section{References:}

[1] M Haider et al. Ultramicroscopy108 (2008) 167-178.

[2] C Kieslowski et al., Microsc. Microanal. 14 (2008) 469-477.

[3] OL Krivanek et al., Microscopy 62 (2013) 3-21.

[4] N Dellby, OL Krivanek and MF Murfitt, Phys. Procedia 1 (2008) 179-180.

[5] H Sawada et al., Micron, in press (2014) http://dx.doi.org/10.1016/j.micron.2014.01.007

[6] OL Krivanek, N Dellby and MF Murfitt, in: Handbook of Charged Particle Optics (2nd edition),

(Orloff J., ed. Boca Raton: CRC Press, 2009) 601-640.

[7] Z Shao, V Beck and AV Crewe, J. Appl. Phys. 64 (1988) 1646-1651.

[8] MFC is supported by the U.S. DOE, Basic Energy Sciences, MSE Division.

[9] $\mathrm{YAlO}_{3}$ sample courtesy Scintillation Materials Research Center at the University of Tennessee.

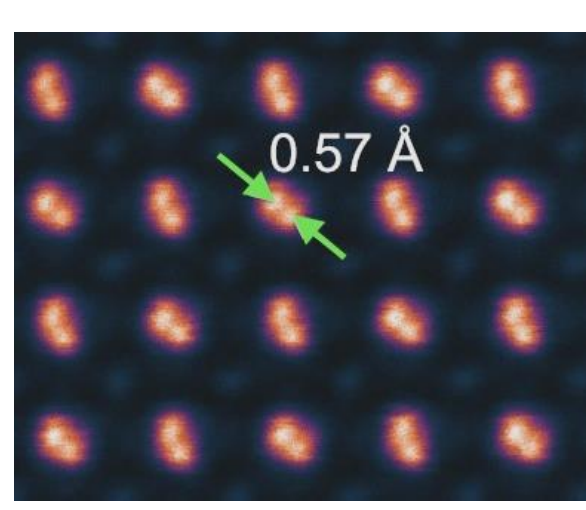

\begin{tabular}{|c|c|c|c|c|c|c|c|c|c|}
\hline \begin{tabular}{|l} 
line \\
umber
\end{tabular} & nu & $\mathbf{m u}$ & nv & $\mathbf{m v}$ & N1 & MI & $\mathbf{N} 2$ & M2 & principal effect \\
\hline 1 & 0 & 1 & 2 & 3 & 1 & 2 & - & - & $\mathrm{Cl}, 2$ \\
\hline 2 & 0 & 1 & 3 & 0 & 2 & 1 & - & - & $\mathbf{C 2 , 1}$ \\
\hline 3 & 0 & 1 & 3 & 4 & 2 & 3 & - & - & $\mathbf{C 2 , 3}$ \\
\hline 4 & 2 & 3 & 2 & 3 & 3 & 0 & - & - & C3,0 \\
\hline 5 & 3 & 0 & 3 & O & 5 & 0 & - & - & $\mathbf{C 5 , 0}$ \\
\hline 6 & 2 & 1 & 3 & O & 4 & 1 & - & - & $\mathrm{C} 4,1$ \\
\hline 7 & 2 & 1 & 3 & 2 & 4 & 1 & 4 & 3 & $\mathrm{C} 4,1 ; \mathrm{C} 4,3$ \\
\hline 8 & 2 & 3 & 3 & 2 & 4 & 1 & 4 & 5 & $\mathrm{C} 4,1 ; \mathrm{C} 4,5$ \\
\hline 9 & 2 & 1 & 3 & 4 & 4 & 3 & 4 & 5 & $\mathrm{C} 4,3 ; \mathrm{C} 4,5$ \\
\hline $\mathbf{1 0}$ & 2 & 3 & 3 & 4 & 4 & 1 & - & - & $\mathrm{C} 4,1$ \\
\hline 11 & 0 & 1 & 5 & 0 & 4 & 1 & - & - & $\mathbf{C 4 , 1}$ \\
\hline 12 & 3 & 2 & 3 & 4 & 5 & 2 & 5 & 6 & C5,2; C5,6 \\
\hline 13 & 3 & 4 & 3 & 4 & 5 & 0 & - & - & $\mathbf{C 5 , 0}$ \\
\hline
\end{tabular}

Figure 1. $\mathrm{YAlO}_{3}$ in $[010]$ projection. Nion UltraSTEM200, $200 \mathrm{keV}$.

Table 1. Combination aberrations in normal use (lines 1-5), plus examples of control of parasitic aberrations (6-13) 